\title{
Frontal Fibrosing Alopecia Severity Index: A Trichoscopic Visual Scale That Correlates Thickness of Peripilar Casts with Severity of Inflammatory Changes at Pathology
}

\author{
María Abril Martínez-Velasco ${ }^{a} \quad$ Norma Elizabeth Vázquez-Herrera ${ }^{b}$ \\ Cosimo Miscialic Colombina Vincenzic Austin John Maddy ${ }^{\mathrm{c}}$ \\ Daniel Asz-Sigalla Antonella Tosti ${ }^{\mathrm{d}}$ \\ aClínica de Oncodermatología, Universidad Nacional Autónoma de México, Ciudad de México, Mexico; \\ bTecnologico de Monterrey, Monterrey, Mexico; ' Dermatology Division, Department of Experimental, Diagnostic, \\ and Specialty Medicine, University of Bologna, Bologna, Italy; ${ }^{\mathrm{d} D e p a r t m e n t}$ of Dermatology and Cutaneous Surgery, \\ University of Miami Miller School of Medicine, Miami, FL, USA
}

\section{Keywords}

Peripilar cast · Frontal fibrosing alopecia progression ·

Lymphocytic infiltrate - Therapeutic monitoring

\begin{abstract}
Background: Frontal fibrosing alopecia (FFA) is a scarring alopecia that mainly affects postmenopausal women characterized by recession of the frontotemporal hairline and eyebrow loss. Current techniques to assess FFA activity are limited and involve noninvasive tools that assess disease progression or an invasive technique such as scalp biopsies. However, since progression of FFA is very slow, it is very important to develop a noninvasive technique to assess disease activity to monitor treatment response. Objectives: To provide a standardized and objective method to assess FFA activity. Methods: We evaluated the correlation between trichoscopy and pathological features (degree of lymphocytic infiltration) in 20 dermoscopy-guided biopsies of FFA. At trichoscopy, we divided the severity of peripilar casts into
\end{abstract}

\section{KARGER}

() 2018 S. Karger AG, Basel

E-Mail karger@karger.com

www.karger.com/sad
3 grades according to their thickness. To validate the trichoscopic visual scale, we showed the images to 7 dermatologists with interest in hair diseases. Concordance was assessed using the Kendall Tau-b concordance test. Results: A strong correlation between severity of peripilar casts at trichoscopy and degree of lymphocytic infiltrate was observed by the Kendall Tau-b test. Validation showed very good inter- and intraobserver agreement. Conclusion: The trichoscopic visual scale allows noninvasive assessment of scalp inflammation in FFA in different scalp regions and therefore provides optimal guidance for treatment.

(c) 2018 S. Karger AG, Basel

\section{Introduction}

The incidence of frontal fibrosing alopecia (FFA) is increasing and prompt treatment is important to prevent progression to advanced stages [1-4]. However, treatment efficacy assessment is difficult as disease progres- 
Fig. 1. a, b Peripilar cast grade I $(<5$ lymphocytes/field/40×). c, d Peripilar cast grade II (5-10 lymphocytes/field/40×). e, f Peripilar cast grade III ( $>10$ lymphocytes/ field/40x).

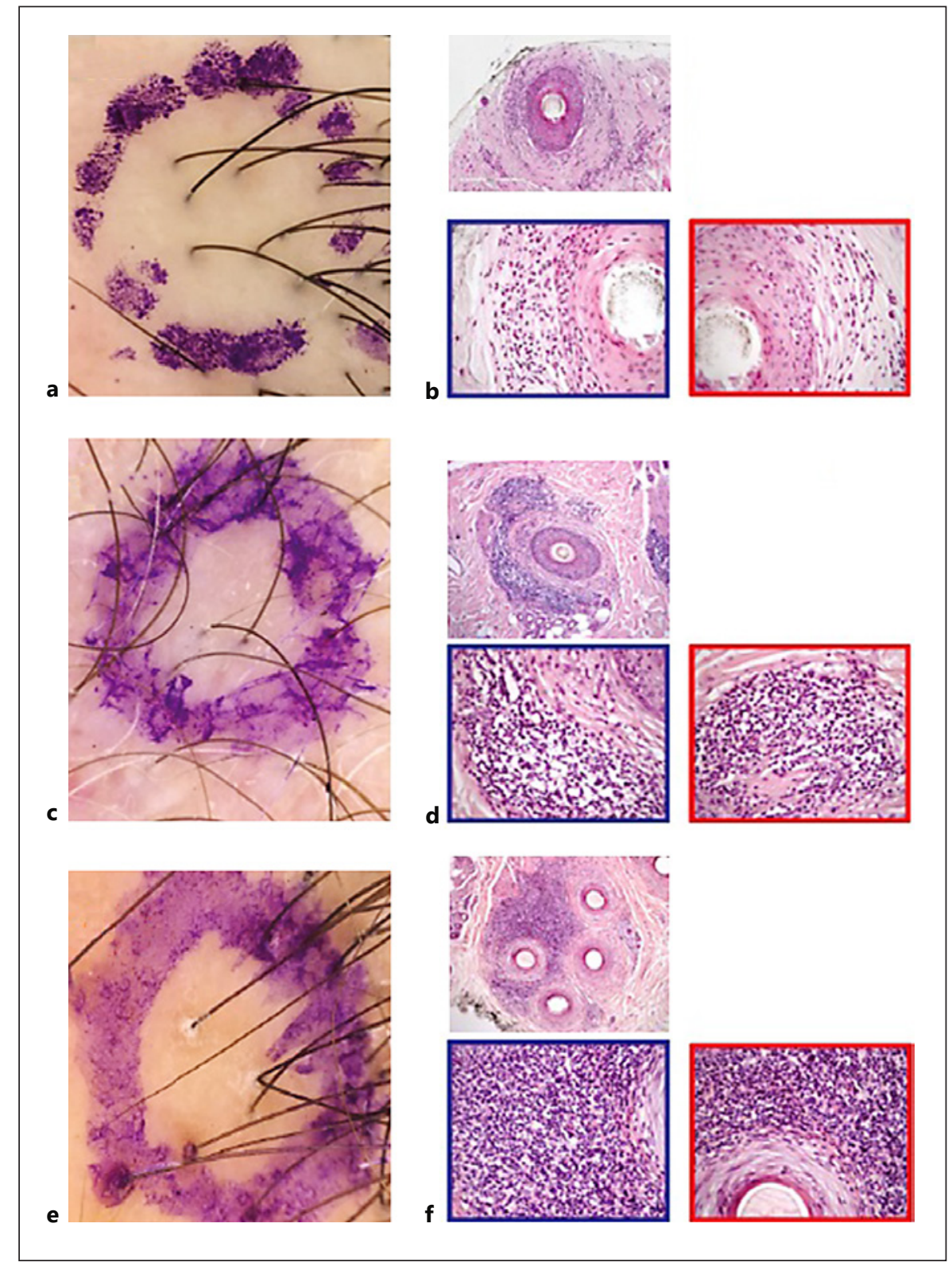

sion is slow and objective methods for evaluating disease activity are not established [5-7]. Perifollicular erythema was proposed as a sign of activity [8], but it can persist in patients who do not present further recession of the hairline while off treatment [9].

FFA activity assessment techniques include scalp biopsies and frontal hairline measurements with the Frontal Fibrosing Alopecia Severity Index (FFASI) [10]. However, scalp biopsies are invasive and cannot be repeated at each visit and FFASI relies on best-fit models and does not evaluate the disease at a microscopic level.
Currently, trichoscopy has become increasingly popular for the diagnosis of different types of scarring alopecia and has shown to be useful in evaluating the activity, progression, and treatment response of FFA [6]. Trichoscopic features of FFA include loss of follicular openings, loss of vellus hairs, peripilar casts, black dots, broken hairs, and pili torti [11].

Peripilar casts are defined as concentrically arranged scales encircling the emerging hair shafts [12].

Although clinicians often notice a positive correlation between the presence of peripilar casts and disease activ- 
Table 1. Results of correlations for the dermatologists with special interest in hair diseases and correlation between peripilar cast thickness and histology

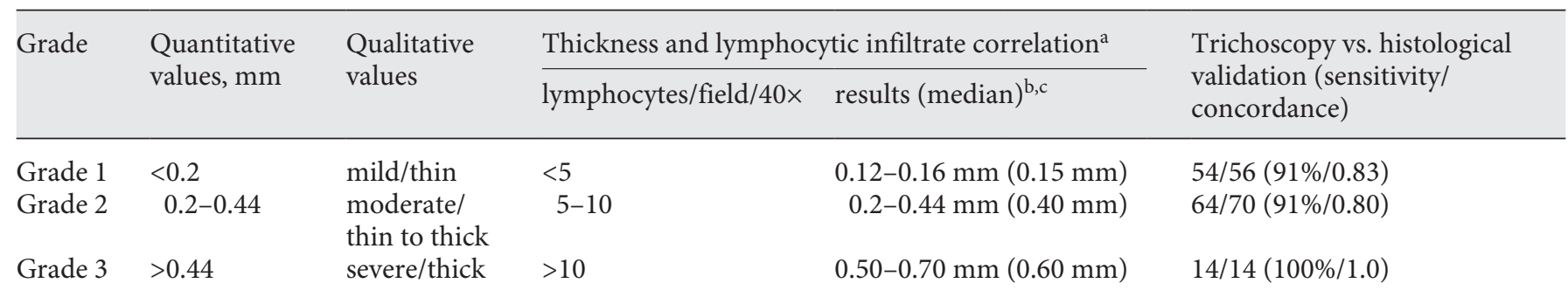

a Thickness of the casts corresponds to the distance from the hair shaft to the outermost site affected on the scalp. ${ }^{\mathrm{b}}$ Kruskal-Wallis $p<0.0001$. $^{\mathrm{c}}$ Spearman correlation of $0.905, p<0.0001$.

ity, there are no studies evaluating the correlation between peripilar casts and severity of the lymphocytic infiltrate in pathology. The aim of this study was to correlate the severity of peripilar casts with the severity of inflammatory infiltrate on dermoscopy-guided scalp biopsies [13, 14].

\section{Methods}

This study was performed in 2 steps. First, we evaluated correlations between trichoscopic and pathological features in 20 dermoscopy-guided 4-mm punch biopsies of FFA.

The degree of lymphocytic infiltrate was evaluated on horizontal sections at the infundibular/isthmic level and scored as mild ( $<5$ lymphocytes/field/40×), moderate (5-10 lymphocytes/field/ $40 \times)$, or severe (>10 lymphocytes/field/40×) [14].

At trichoscopy, we divided the severity of peripilar casts into 3 grades according to their thickness. This was measured using Tricholab software of Fotofinder systems ${ }^{\circledR}$. Cast thickness (thickness from one side to the other) was considered as mild/thin (grade $1 ;<0.2 \mathrm{~mm}$ ), moderate/thin to thick (grade $2 ; 0.2-0.44 \mathrm{~mm}$ ), or severe/thick (grade $3 ;>0.44 \mathrm{~mm}$ ).

The second part of the study consisted in validating the trichoscopic visual scale in a clinical setting. We showed the trichoscopic images to 7 dermatologists with special interest in hair diseases.

Concordance was assessed using the Kendall Tau-b and Spearman test. Concordance less than 0.20 indicated a very poor agreement; $0.21-0.40$, poor agreement; $0.41-0.60$, regular agreement; $0.61-0.80$, good agreement; and 0.81-0.99, excellent agreement. Calculations were performed with SPSS version 21 .

\section{Results}

Correlation between hair cast thickness (Tricholab software) and degree of lymphocytic infiltration was highly significant (Kruskal-Wallis $p<0.0001$, Spearman correlation of $0.905, p<0.0001)$.

Frontal Fibrosing Alopecia Severity Index
A strong correlation between the severity of peripilar casts at trichoscopy and the degree of lymphocytic infiltrate was observed (observers vs. histopathology) with the Kendall Tau-b test (0.88) (Fig. 1a-f; Table 1). Concordance between different observers was high, particularly for grade 3 .

\section{Conclusion}

The only available tool to monitor FFA progression is the FFASI, which is valuable for measuring cicatricial progression, but not the inflammatory activity of the disease [10].

Our study identifies a strong correlation between the severity of peripilar casts and the degree of lymphocytic infiltration on trichoscopy-guided biopsies. The proposed severity grading index of peripilar casts can be utilized to visually assess disease activity in different scalp areas, which is important to select the areas that need intralesional infiltration and to monitor treatment response at follow-up.

A limitation of this study is that we only focused on peripilar casts, as dermoscopy-guided biopsies are taken in areas showing signs of disease activity in order to maximize chances of correct pathological diagnosis [13]. Therefore, we do not include scalp areas with advanced scarring.

An opportunity for further studies could establish a parallel score to the FFASI scale established by Holmes et al. [10], which considers the topographic involvement of FFA measured by quadrants. Mapping the area using the FFASI scale can identify the quadrants of active inflammation that need topical or intralesional treatment. 


\section{Acknowledgements}

We thank Hubert Łącki from Tricholab for measuring peripilar cast characteristics, used in the development of the scale criteria, and Enrique Berrios for his help in the data processing and statistical analysis.

\section{Statement of Ethics}

All procedures followed were in accordance with the ethical standards of the responsible committee on human experimentation (institutional and national) and with the Helsinki Declaration of 1964 , as revised in 2013.

\section{Disclosure Statement}

Dr. Antonella Tosti - P and G: Consultant; DS Laboratories: Consultant; Incyte: PI; Pfizer: PI; Fotofinder: Consultant; Springer, Taylor and Francis: Author royalties; Karger: Editor in chief; National Alopecia Areata Foundation: Scientific Board.

All other authors have nothing to disclose.

\section{References}

1 MacDonald A, Clark C, Holmes S: Frontal fibrosing alopecia: a review of 60 cases. J Am Acad Dermatol 2012;67:955-961.

$\checkmark 2$ Tan KT, Messenger AG: Frontal fibrosing alopecia: clinical presentations and prognosis. Br J Dermatol 2009;160:75-79.

3 Ladizinski B, Bazakas A, Selim MA, Olsen EA: Frontal fibrosing alopecia: a retrospective review of 19 patients seen at Duke University. J Am Acad Dermatol 2013;68:749-755.

4 Vañó-Galván S, Molina-Ruiz AM, SerranoFalcón C, Arias-Santiago S, Rodrigues-Barata AR, Garnacho-Saucedo G, et al: Frontal fibrosing alopecia: a multicenter review of 355 patients. J Am Acad Dermatol 2014;70:670678.

5 Rácz E, Gho C, Moorman PW, Noordhoek Hegt V, Neumann HAM: Treatment of frontal fibrosing alopecia and lichen planopilaris: a systematic review. J Eur Acad Dermatology Venereol 2013;27:1461-1470.
-6 Fernández-Crehuet P, Rodrigues-Barata AR, Vañó-Galván S, Serrano-Falcón C, MolinaRuiz AM, Arias-Santiago S, et al: Trichoscopic features of frontal fibrosing alopecia: results in 249 patients. J Am Acad Dermatol 2015;72: 357-359.

7 Vazquez-Herrera NE, Eber AE, MartinezVelasco MA, Perper M, Cervantes J, Verne $\mathrm{SH}$, et al: Optical coherence tomography for the investigation of frontal fibrosing alopecia. J Eur Acad Dermatology Venereol 2017, Epub ahead of print.

8 Toledo-Pastrana T, Hernández MG, Camacho Martínez F: Perifollicular erythema as a trichoscopy sign of progression in frontal fibrosing alopecia. Int J Trichology 2013;5:151.
9 Banka N, Mubki T, Bunagan MJK, McElwee $\mathrm{K}$, Shapiro J: Frontal fibrosing alopecia: a retrospective clinical review of 62 patients with treatment outcome and long-term follow-up. Int J Dermatol 2014;53:1324-1330.

10 Holmes S, Ryan T, Young D, Harries M; British Hair and Nail Society: Frontal Fibrosing Alopecia Severity Index (FFASI): a validated scoring system for assessing frontal fibrosing alopecia. Br J Dermatol 2016;175:203-207.

11 Tosti A: Dermoscopy of the Hair and Nails, ed 2. Boca Raton, CRC Press, 2016, pp 53-56.

12 Miteva M, Tosti A: Hair and scalp dermatoscopy. J Am Acad Dermatol 2012;67:10401048.

13 Miteva M, Tosti A: Dermoscopy guided scalp biopsy in cicatricial alopecia. J Eur Acad Dermatology Venereol 2013;27:1299-1303.

14 Tosti A, Piraccini BM, Iorizzo M, Misciali C: Frontal fibrosing alopecia in postmenopausal women. J Am Acad Dermatol 2005;52:55-60. 